\title{
Sensitivity analysis of influencing factors in probabilistic risk assessment for airports
}

\author{
Misagh Ketabdari ${ }^{a}$, Filippo Giustozzi ${ }^{\text {b,* }}$, Maurizio Crispino ${ }^{\mathrm{a}}$ \\ ${ }^{a}$ Transportation Infrastructures and Geosciences Section, Department of Civil and Environmental Engineering, Politecnico di Milano, 20133 Milan, Italy \\ ${ }^{\mathrm{b}}$ Civil and Infrastructure Engineering, Royal Melbourne Institute of Technology - RMIT University, Melbourne, VIC 3001, Australia
}

\section{ABSTRACT}

Risk assessment methods in aviation greatly rely on the knowledge of the factors influencing risk and safety during daily operations. One of the weak points of the common approaches in aerodromes is the qualitative method to support decisions respect to quantitative evaluations. In this study, three air-ports with diverse characteristics (i.e.; aircraft annual movements, airfield geometry, and runway features) were selected for the analysis.

The RSARA $\odot$ (Runway Safety Area Risk Assessment) software, which is based on the Aircraft Cooperative Research Program (ACRP) model, has been utilized as a starting point for further sensitivity analyses of probabilistic risk assessment of each airport's runway with determined casual factors, includ-ing runway geometry, traffic characteristics, and weather conditions. A comprehensive airports incident/accident database between years 2000 and 2015 was also used to perform the sensitivity analyses.

By providing different independent variables as input in the frequency model of RSARA, the outputs were useful to determine the influence of each of the casual factors on the accident probability of occur-rence. Selected variables include: runway length in terms of declared distances, Runway Safety Area geometry, instrumental landing system category, weather operational data and annual traffic growth rate. The sensitivity analyses showed that the weather condition and runway related factors played a major role in increasing or decreasing the probability of the accident; the probability of landing overrun (LDOR) can be increased by four times, for instance, due to specific combinations of runway length and climatic conditions. Engineered arrestor beds such as EMAS also has the potential to decrease by 50\% the risk of LDOR and can be selected as an effective choice compared to other pavement materials within the RSA.

Identifying critical variables on the occurrence of high-severity runway accidents could influence the aerodrome design, operating scenarios, regulations, emergency planning and risk management measures and techniques.

\section{Introduction}

Fatality, injuries, and damage are important topics of all transport safety policies; performing systemic risk assessment is therefore inevitable. In this regard, safety strategies are to be developed and applied on the system and frequent monitoring is needed to assist in developing comprehensive safety policies for various transport modes such as rail, road, air and maritime (de Castro Fortes and Correia, 2012).

Aerodrome is considered a complex system, assessing risk in aviation would thus use complex procedures. This assessment

* Corresponding author.

E-mail addresses: misagh.ketabdari@polimi.it (M. Ketabdari), filippo.giustozzi@rmit.edu.au (F. Giustozzi), maurizio.crispino@polimi.it (M. Crispino). greatly relies on the acquisitive knowledge of the factors influencing the risk and the safety buffer that needs to be designed in order to achieve an acceptable level of safety in daily operations and movements. One of the weak points of prior approaches to manage risk in aerodromes is their large dependency on judgmental and qualitative decisions. Less subjectivity can be obtained by evaluating the direct and indirect impacts of different factors affecting both the airport and the aircraft.

Aviation performances can be divided into two categories of operation; normal operation with stochastic variations in performance and abnormal operation (Trucco et al., 2015). Measures to be employed for increasing safety could be categorized as passive or active measures. Passive measures may stand for taking care of more extreme and unpredictable hazards, in contrast active 
measures cover the expected stochastic variations in normal operations.

The International Civil Aviation Organization (ICAO) has strengthened its standards and recommendations for the geometry of the Runway Safety Area (RSA) in airports (Annex 14, ICAO 2013). The surface beyond the end of a runway which is available to protect an overrunning or undershooting aircraft consists of a $60 \mathrm{~m}$ strip plus the Runway End Safety Area (RESA). Prior ICAO standard accepted smaller RESA but this was extended in current regulations (Annex 14, ICAO 2013). Although newer standards can have positive impacts on increasing safety, implementing them can cause significant costs to the airport authority. In some cases extending the RSA is not even possible for airports which are landlocked or face challenges due to terrain or environmental restrictions, such as wetlands. A greater knowledge about the analytical assessment of the probability of possible hazards and corresponding consequences is thus fundamental.

Landing and take-off phases of flight are experienced as including the major portion of air accidents (Guerra et al., 2008). The reason behind these events is mainly loss of aircraft control and surpassing the designated thresholds and safety areas. In general, common possible accidents that occur during these flight phases can be categorized as landing overrun (LDOR), landing undershoot (LDUS), landing veer-offs (LDVO), take-off overrun (TOOR), and take-off veer-offs (TOVO).

Regulations and requirements (Valdés et al., 2011) for designing safety areas in the proximity of the runway aim to decrease the probability of these types of accidents and mitigate their possible consequences. In this study, a set of influencing factors which would affect the probability of risk related to associate types of events was investigated.

\section{Literature review and reference model selection}

Nowadays, the definition of safety gets more comprehensive and it is described as the decreasing likelihood of harm to properties or persons which has to be kept under an acceptable level through a continue process of hazard identification (ICAO, 2013).

From previous studies and recorded accident data, it can be interpreted that LDOR, LDUS, LDVO, TOOR, and TOVO formed the major portion of the accident that occurred in the surrounding areas of the runway. Statistical records from 1959 to 2009 shows that $55 \%$ of world-wide aircraft accidents occurred during landing and take-off phases (Boeing, 2016). It is obvious that human and organizational errors play a big role in occurrence of these types of accidents but airport and runway conditions also contribute significantly to generate potential risk.

According to the Federal Aviation Administration, "The runway safety area (RSA) is a graded and obstacle-free rectangular-shaped area surrounding the runway that should be capable, under normal (dry) conditions, of supporting airplanes without causing structural damage to airplanes or injury to their occupants" (AC $150 / 5300-13,1989)$. RSA can be divided into three sections depending on the type of accidents that may occur in the proximity of the runway. Two sections are located at the runway ends; these sections would help to mitigate the possible consequences of aircraft overrunning and undershooting the runway. The third RSA section is located in the lateral areas of the runway. This area should reduce the severity of aircraft veer-off incidents.

Assessing risk required both specific tools, which need to assign probability values to specific accidents, and models, which are able to estimate consequences of such events. Several accident probability models have been developed in the last decades. Eddowes et al. (2001) published a report concerning risk analysis in support of aerodrome design rules. Kirkland et al. (2003) focused on incident data collection and normalization to develop estimation of probability of occurrence, location of wreckage and assessment of the consequences. However, those studies suffered from the same limitation due to the database restriction, which only included the Historical accident Operational Data (HOD). In fact, in order to understand the effects of different variables on occur-rence frequency of the accidents, sensitivity analyses should be performed on both accident database and non-accident flights movements. This latter is feasible only in existence of Normal Operational Data (NOD), not commonly available.

In 2008, the Airport Cooperative Research Program (ACRP) published the "Analysis of Aircraft Overruns and Undershoots for Runway Safety Areas" (ACRP report 3, 2008). The report investigated the average probability of accident occurrence during landing and take-off; more influencing factors on risk probability calcula-tion were taken into account compared to previous models, thus increasing the accuracy of this procedure. Normal operational data was also included besides accident/incident database.

In 2009, (Wong et al., 2009) used a frequency model based on specific accident types providing a comprehensive database of all possible accident types. Furthermore, the wreckage location model was developed based on cumulative recorded accidents location frequency, instead of on the actual landing and take-off kinetic energy modeling.

In 2011, probabilistic and risk models related to historical accident operational data have been proposed by (Valdés et al., 2011). Moreover, two studies on runway excursions were conducted by ACRP (ACRP, 2008, 2011), which applied traditional logistic regression to predict the probability of occurrence of runway excursion.

In 2014, (Wagner and Barker, 2014) used logistic regression and Bayesian logistic regression to model runway excursions. The authors of this study focused more on predicting the possibility of generating fatalities as a consequence of excursion occurrence more than predicting the type of runway excursion. Their effort aimed to model fatal airport runway excursions, define mitigation measures to accidents occurrence and their severities, and verify the efficacy of risk management strategies that were employed.

In 2013, a study from (Roelen and Blom, 2013) analyzed the evolvement of safety performance regards to runway airplane maneuver over the period 1990-2008. Statistical data records of worldwide accidents of commercial flights by fixed-wing aircraft with a maximum take-off weight of more than $5700 \mathrm{~kg}$ were selected as the boundary conditions. The output showed that the accidents occurrence rate related to Take-Off and Landing does not identify a clear positive or negative trend over the period 19902008.

While most of the previous models gave single probability values as the output, in 2015 Trucco et al. proposed a methodology which contains a two-step procedure and returns probability and severity results in the form of a topological grid as output. Therefore, by superimposing this topological risk grid on the terrain surrounding the runway it would have been possible to plan the mitigation measures, reduce the probability of occurrence and the possible consequences; these, in one word, correspond to the risk of accident on the infrastructure (Trucco et al., 2015).

Based on the strength and weaknesses of prior models, the ACRP accident formula is used for this study as the reference base model. This preference is related to the large amount of data upon which this model was built. Using normal operation data allowed to quantify the importance of each factor and the way it specifi-cally influences the final accident probability. Several influencing factors were considered both from traffic characterization and impact of weather conditions on the runway (NTSB, 2005). 


\section{Statistical sensitivity analysis on real-data database}

Two databases that contain a significant number of relevant accidents and incidents on and near runway during Landing and Take-off phases of flight were created for this study. Accident/Incident recorded data were collected from reliable data sources. National Transportation Safety Board Accident Database and Synopses (NTSB) is the main source of data (NTSB, 2014). In addition, part of the data was complemented from other sources of information consisting of world aero-data database and sky vector aeronautical charts. This was particularly needed to know the category of airports according to ICAO, runway information and availability of Instrumental Landing System (ILS).

Furthermore, sensitivity analyses were conducted on different parameters to find out their level of significance. Total of 30,174 accident/incident data records were analyzed. Airplanes with two or more engines and landing and take-off phases were selected.

\subsection{Data sample description}

For each individual event the database included the event date, investigation type, accident number, country/location, airport code and category, number of runways, direction of the runway, navigational aids NAVAID, aircraft category, model of the aircraft, number of engines, weather condition, latitude and longitude.

Between the years 2000 and 2015, the total number of accidents and incidents data collected was 30,174. The first filtration was done by location; in this case, the events which occurred in the US were 27,094 and it was decided to only use those entries to avoid inconsistencies among different database systems. The sec-ond filtration criterion was the number of engines; airplanes with two and more than two engines were only considered in the anal-ysis and the resulting events number was reduced to 3480 . The third filtration criterion was done by deleting the events related to helicopters, balloons and turboprops. After the third filtration 3366 events remained. Finally, landing and take-off were chosen as the only phases of the flight to be considered. The resulting fil-tered events were 1329 of which 776 occurred during landing phase and 553 dedicated to the take-off phase. Fig. 1 shows the number of events between the years 2000 and 2015 according to the filtration.

\subsection{Statistical sensitivity analysis}

\section{- Event type and phases of the flight}

$87.6 \%$ of the landing events and $79.9 \%$ of the take-off events were accidents. This statistics indicates only the accidents and incidents which were reported and stored in the database. However, incidents occur more frequently than accidents although the majority of the incidents were not registered, since they did not cause significant property damage or loss of lives.

Fig. 2 shows the accidents and incidents in all phases of flight except landing and take-off. Likewise to previous results, the number of reported accidents is greater than the incidents.

The number of reported accidents during landing is higher than the number of accidents during the take-off phase. Figs. 3 and 4 show the accidents and incidents during landing and take-off phases, respectively.

\section{- Meteorological conditions and event type}

Aviation meteorological conditions can be labeled as Visual Meteorological Condition (VMC) and Instrumental Meteorological Condition (IMC). VMC is the aviation flight category in which Visual Flight Rules (VFR) are permitted. In these conditions pilots have sufficient visibility to fly the aircraft maintaining visual separation from terrain and other aircrafts. In contrary, IMC is an aviation flight category that describes weather conditions that require pilots to fly primarily by reference to instruments, and therefore under Instrument Flight Rules (IFR) (ICAO annex 6 part 1, 2010).

From the total of 776 events occurred between 2000 and 2015 during landing, 674 (87\%) of them occurred during VMC and 102 (13\%) during IMC. For the take-off phase, 492 (89\%) occurred in VMC and 61 (11\%) in IMC. During VMC conditions the major role is played by the pilot if there are no other factors leading the speci-fic flight to accident or incident. This indicates that the weather condition is not the main cause of the accidents or incidents. The numbers of events during IMC are low, thus indicating that the instruments used for the navigation helped to reduce both the probability of occurrence of the events and their severity, even during bad weather.

A greater number of events occurred during landing compared to takeoff phase in VMC, Figs. 5 and 6.

\section{- FAA airport category and the events}

FAA airport categorization defines airports as Primary Large Hub (P-L), Primary Medium Hub (P-M), Primary Small Hub (P-S), Primary Non Hub (P-N), Non-Primary Commercial Service (CS), Reliever Airports (R), and General Aviation Airports (GA).

The P-CS and the GA airports have approximately equal number of events during landing phase as shown in Table 1 and Fig. 7. The P-CS has greater event number than the GA in the take-off phase as shown in Table 2 and Fig. 8. The primary reasons for the large number of events occurrence in P-CS is the higher annual traffic by means of number of movements. In addition, most of the GA airports are not equipped with navigational aids and other advanced facilities similar to the primary airports; this is one of

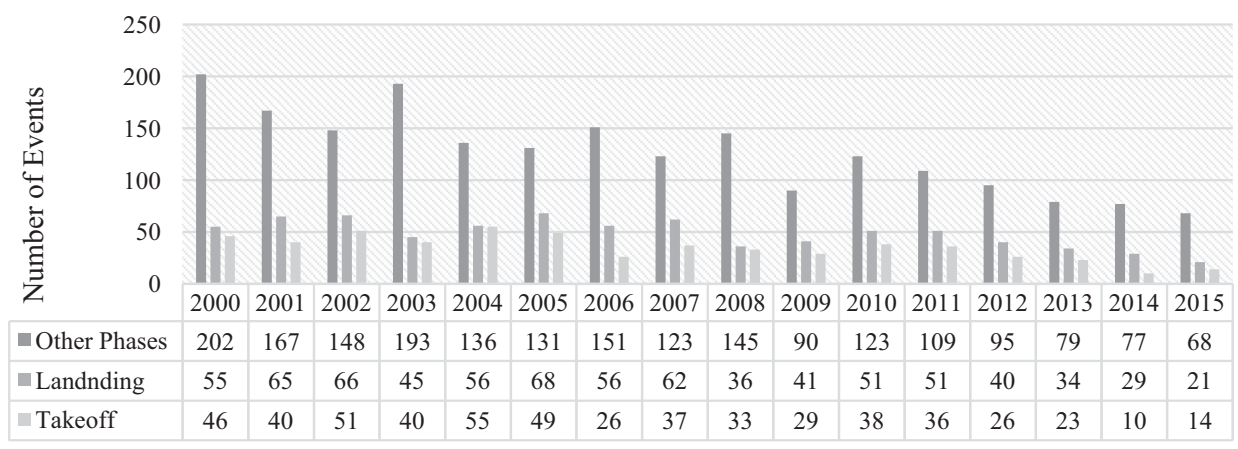

Fig. 1. Number of events of landing, take-off and number of events in all other phases of flight. 


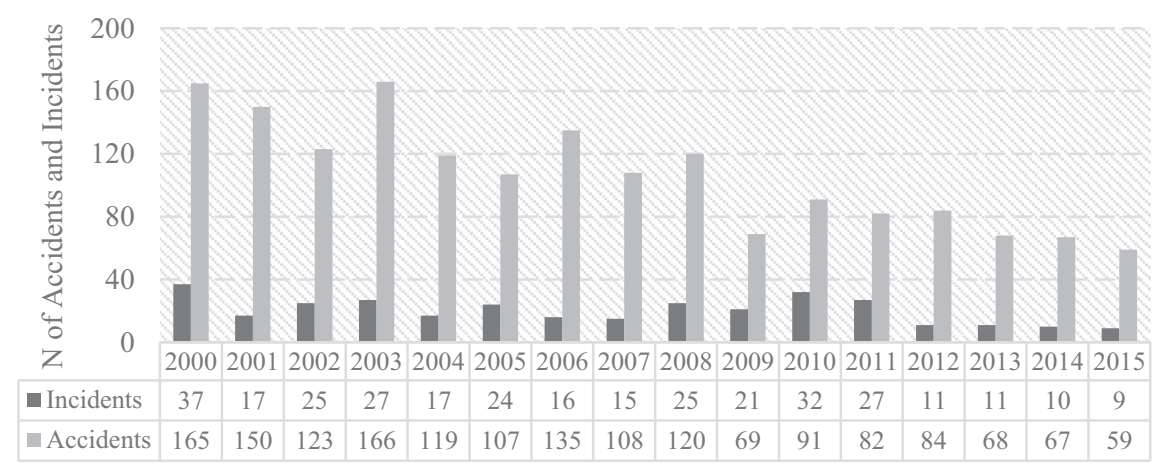

Fig. 2. Types and number of events in all phases of the flight except landing and take-off.

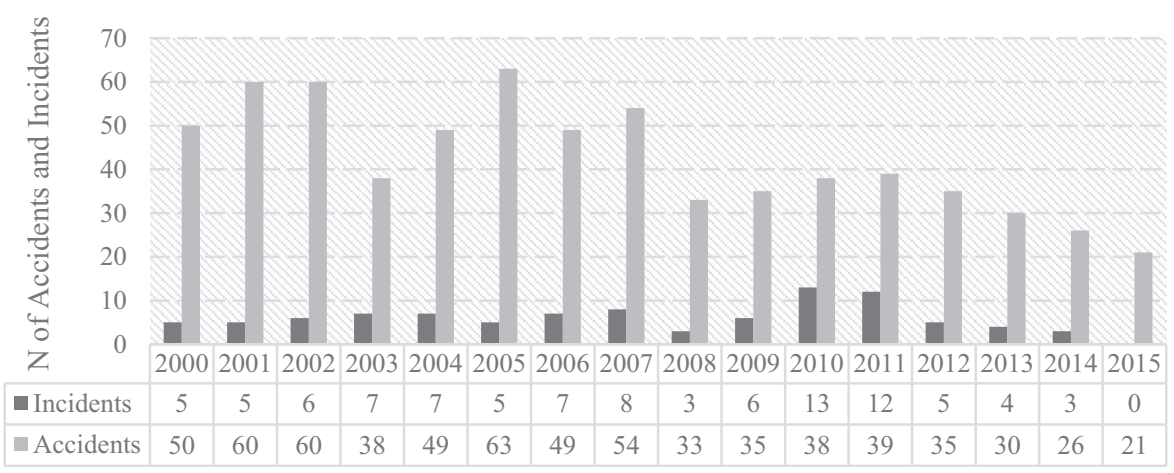

Fig. 3. Types and number of events during landing.

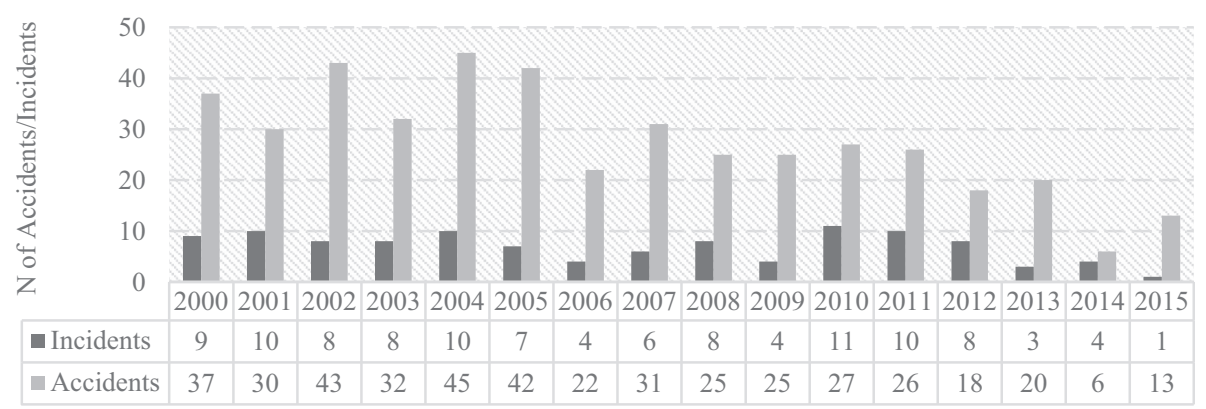

Fig. 4. Types and number of events during take-off.

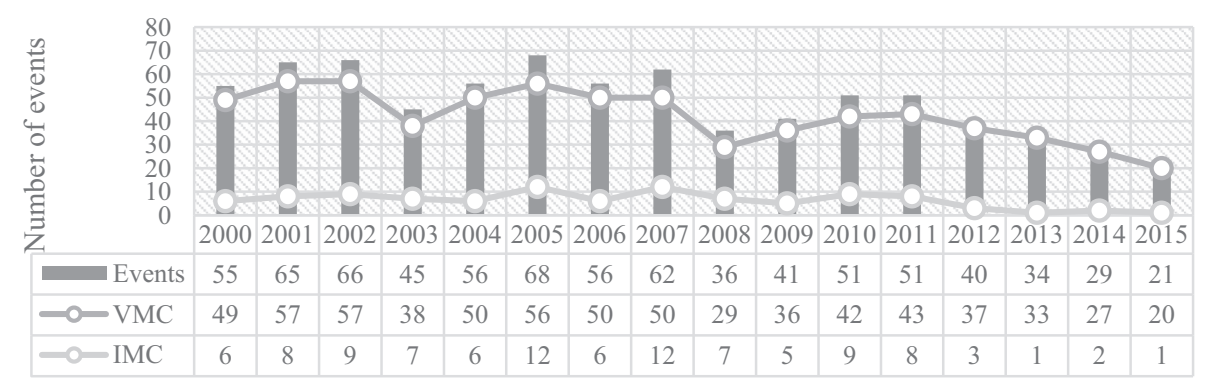

Fig. 5. Meteorological conditions and number of events which occurred during landing.

the reasons for having a large number of events occurrence despite the relatively lower traffic. Pie charts (Figs. 7 and 8) show the percentage of the events for the main FAA airport categories and the PCS category in further detail.

\section{- Presence of ILS}

Instrumental Landing System (ILS) is used in airports to assist the aircraft to land properly during difficult weather conditions 


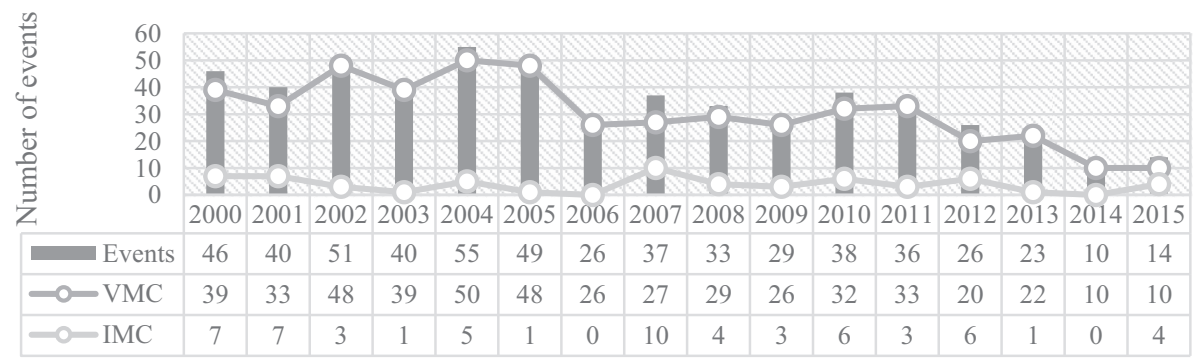

Fig. 6. Meteorological conditions and number of events which occurred during take-off phase of flight.

Table 1

FAA main airport categories and the number of events in landing phase of flight.

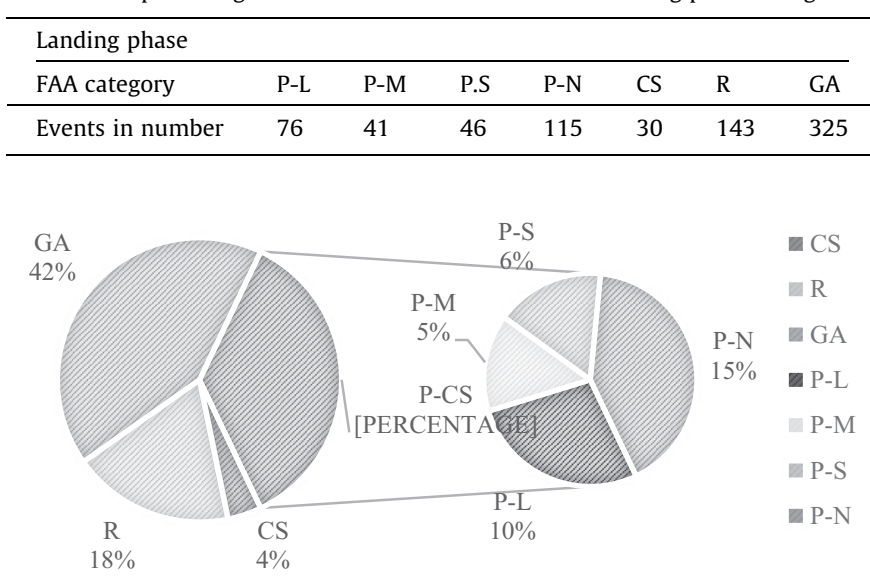

Fig. 7. FAA airport categories and the percentage of events in landing phases of flight.

Table 2

FAA main airport categories and the number of events in take-off phase of flight.

\begin{tabular}{llllllll}
\hline Take-off phase & \multicolumn{1}{l}{} \\
\hline FAA category & P-L & P-M & P.S & P-N & CS & R & GA \\
\hline Events in number & 92 & 30 & 39 & 72 & 26 & 114 & 180 \\
\hline
\end{tabular}

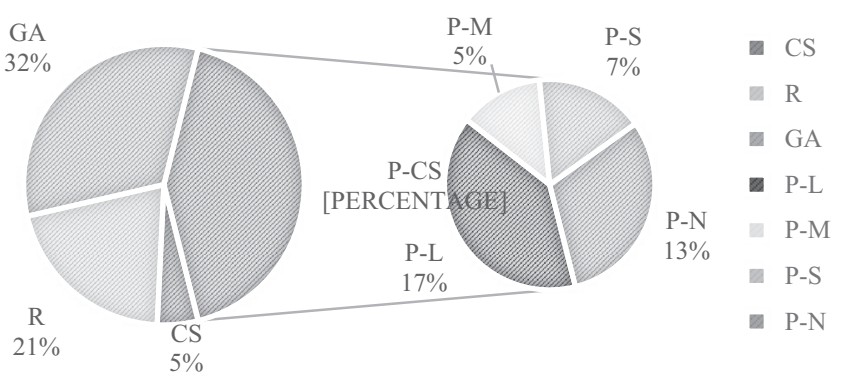

Fig. 8. FAA airport categories and the percentage of events in take-off phases of flight.

or every time the pilot requires it. The number of events in airports where ILS is active, are less than the number of events in airports without ILS. This outcome is indeed completely realistic. To make a better comparison, the weather condition is also included in addition to the presence of the ILS to make more reasonable correlation between influencing factors.

Interesting data pattern can be extracted from Fig. 9. It can be noted that most of the events in airports with ILS occurred during visual meteorological conditions when the ILS system is likely not in use while really small number of events occurred during IMC. From these results it can be concluded that ILS shows a great improvement to the reduction of accident occurrence in instrumental meteorological conditions.

\section{Methodology - ACRP reference model}

This research and all the related computations are based on ACRP accident probability methodology which had been reported in ACRP report 50 (ACRP report 50, 2011). In addition, Runway Safety Area Risk Analysis software - RSARA (Ayres et al., 2013) - has been used to operate the simulations of the accident probability and sensitivity analysis of influencing factors. RSARA was developed by Airport Cooperative Research Program (ACRP), and the models for risk assessment of RSA have been improved in project ACRP 4-08 (ACRP report 50, 2011). This simulator is intended to serve as a tool to assist airport operators in evaluating the risks associated with their RSA conditions.

Although in most of the cases aircrafts stop inside the determined runway boundaries, there are also rare events in which the aircraft is not capable to stop within the physical limits and overrun the runway or adjacent safety areas leading to incidents or accidents. The probability distribution of aircraft overrunning the runway and stop location probability distribution at the end of the runway and the relevant formula is depicted in Fig. 10(a) (Valdés et al., 2011).

Similarly, during landing, aircrafts would touchdown right after the aiming point indicated on the runway in most of the cases. However, in some cases and under certain undesired conditions, aircrafts could touch the ground before the runway paved threshold thus increasing the risk and associate consequences of crashes (Valdés et al., 2011). In Fig. 10(b) the probability distribution of aircraft landing undershoot and touchdown location probability distribution and the relevant formula is provided.

The assessment of associate risk of runway and runway safety area in the ACRP methodology consists of developing three risk sub-models for each possible type of accidents. Generally, by correlating the probability of accident model to probability distribution of accident wreckage location on or around runway and associate possible consequences, model risk assessment would be performed.

The analysis of RSA risk requires three sub-models that consider (1) probability (frequency), (2) location and (3) consequences. As a result of the correlation analysis between these models, the risk of accident during runway excursions and undershoots would be achieved. The three-risk model approach is represented in Table 3.

\subsection{Hazard probability model}

The first model is used to calculate the occurrence probability of a possible hazard during specific operational conditions. This 


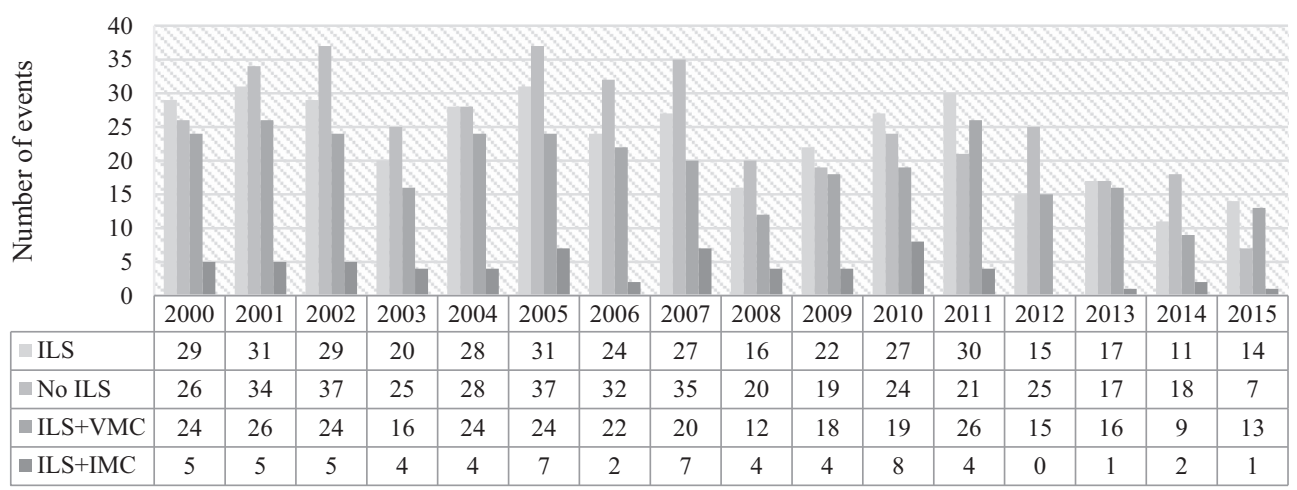

Fig. 9. Number of events in airports with/without ILS with respective weather condition (VMC/IMC).

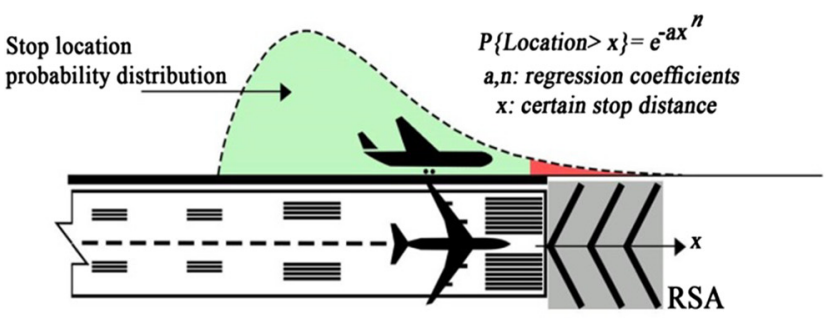

(a)

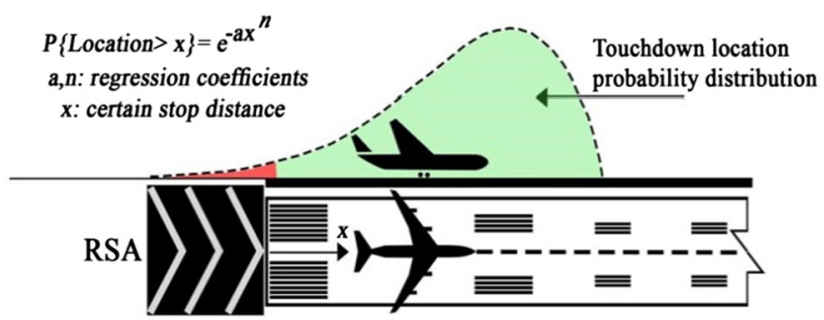

(b)

Fig. 10. Reference scheme for the FAA ACRP for (a) Stop location probability distribution and (b) Touchdown location probability distribution.

Table 3

Structure of three probability models required for RSA risk assessment according to ACRP methodology.

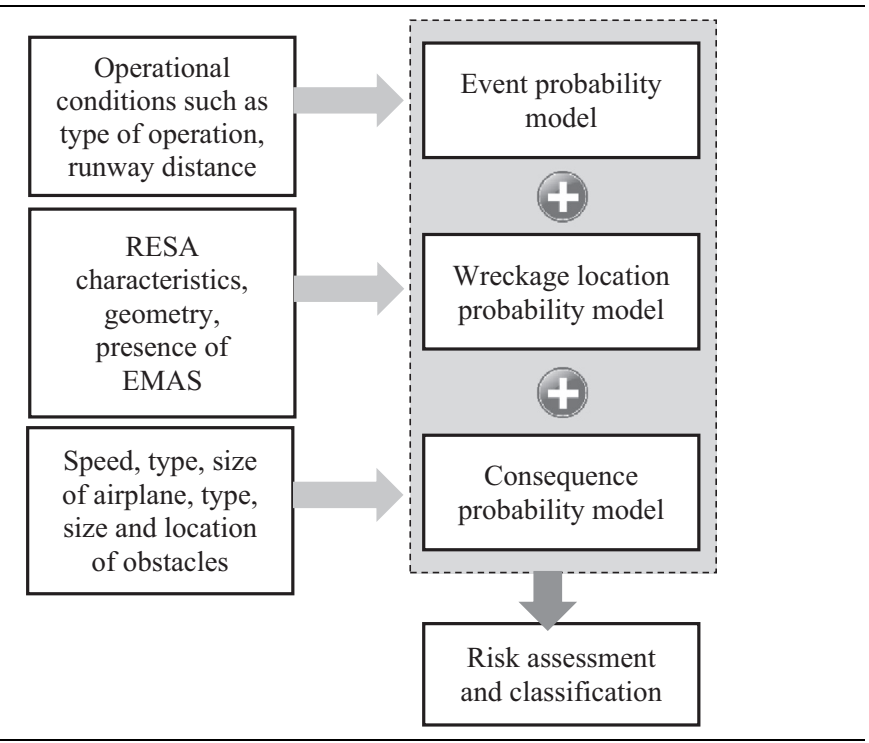

model only estimates the probability of event occurrence but does not provide the wreckage location or possibility of staking any obstacles.

Only certain parameters, which are relevant to the causalities of the accident, are used. For instance, the probability of overrunning the runway would increase under tailwind and decrease according to headwind.

There are specific frequency models' equations for each of the five types of accident; LDOR, LDUS, LDVO, TOVO, and TOOR. In this methodology backward step-wise logistic regression was used to calibrate these five frequency models.

Taking advantage of actual incident/accident database, normal operational data were preferred for developing this probability model. The outcome from the model application will assist in evaluating the possibility of event occurrence that is subject to certain traffic and climate conditions over a period of time.

One of the weak points of this methodology is the unavailability to directly incorporate human and organizational errors into the risk model, although these factors are identified as to be among the most important causes of aircraft accidents.

The frequency model in a logistic format offered by ACRP report 50 (2011) has been used in this study. The frequency model is described by the following equation:

$P\{$ Accident_Occurence $\}=\frac{1}{1+e^{-\left(b_{0}+b_{1} X_{1}+b_{2} X_{2}+b_{3} X_{3}+\ldots\right)}}$

Which P\{Accident Occurrence $\}$ is the probability of a specific type of accident occurring (i.e.; LDOR) in certain operational conditions, Xi are independent variables (e.g., ceiling, visibility, crosswind, precipitation, aircraft type, criticality factor), and $b_{i}$ are the regression coefficients (Ayres et al., 2013).

The values of regression coefficients for the frequency model are provided in Table 4. Regression coefficients have been devel-oped for each type of event using Normal Operational Data (NOD) and backward stepwise procedure. Moreover, independent variables were converted to binary form to avoid non-linear relationships between the model's components. Binary variables can only take into account two values, 0 or 1 ; in the presence of the specific event (e.g., rain) the variable assumes a value of 1 , while in the absence of the specific event (e.g., no rain) the variable is 0 (ACRP report 50, 2011). 
Table 4

Reference table for the FAA - ACRP for regression coefficients values used for frequency model.

\begin{tabular}{|c|c|c|c|c|c|}
\hline Regression coefficients values & LDOR & LDUS & LDVO & TOOR & TOVO \\
\hline Adjusted Constant & -13.065 & -15.378 & -13.088 & -14.293 & -15.612 \\
\hline User Class $^{\mathrm{a}} \mathrm{F}$ & & 1.693 & & 1.266 & \\
\hline User Class G & 1.539 & 1.288 & 1.682 & & 2.094 \\
\hline User Class $\mathrm{T} / \mathrm{C}$ & -0.498 & 0.017 & & & \\
\hline Aircraft Class A/B & -1.013 & -0.778 & -0.770 & -1.150 & -0.852 \\
\hline Aircraft Class $\mathrm{D} / \mathrm{E} / \mathrm{F}$ & 0.935 & 0.138 & -0.252 & -2.108 & -0.091 \\
\hline Ceiling less than $200[\mathrm{ft}]$ & -0.019 & 0.070 & & 0.792 & \\
\hline Ceiling 200-1000 [ft] & -0.772 & -1.144 & & -0.114 & \\
\hline Ceiling $1000-2500[\mathrm{ft}]$ & -0.345 & -0.721 & & & \\
\hline Visibility less than 2 [SM] & 2.881 & 3.096 & 2.143 & 1.364 & 2.042 \\
\hline Visibility from 2 to 4 [SM] & 1.532 & 1.824 & & -0.334 & 0.808 \\
\hline Visibility from 4 to 8 [SM] & 0.200 & 0.416 & & 0.652 & -1.500 \\
\hline Crosswind from 5 to 12 [kt] & -0.913 & -0.295 & 0.653 & -0.695 & 0.102 \\
\hline Crosswind from 2 to 5 [kt] & -1.342 & -0.698 & -0.091 & -1.045 & \\
\hline Crosswind more than 12 [kt] & -0.921 & -1.166 & 2.192 & 0.219 & 0.706 \\
\hline Tailwind from 5 to 12 [kt] & & & 0.066 & & \\
\hline Tailwind more than 12 [kt] & 0.786 & & 0.980 & & \\
\hline Temp less than $5\left[{ }^{\circ} \mathrm{C}\right]$ & 0.043 & 0.197 & 0.558 & 0.269 & 0.988 \\
\hline Temp from 5 to $15\left[{ }^{\circ} \mathrm{C}\right]$ & -0.019 & -0.710 & -0.453 & -0.544 & -0.420 \\
\hline Temp more than $25\left[{ }^{\circ} \mathrm{C}\right]$ & -1.067 & -0.463 & 0.291 & 0.315 & -0.921 \\
\hline Icing Conditions & 2.007 & 2.703 & 2.670 & 3.324 & \\
\hline Rain & & 0.991 & -0.126 & 0.355 & -1.541 \\
\hline Snow & 0.449 & -0.250 & 0.548 & 0.721 & 0.963 \\
\hline Frozen Precipitation & & & -0.103 & & \\
\hline Gusts & & 0.041 & -0.036 & 0.006 & \\
\hline Fog & & & 1.74 & & \\
\hline Thunderstorm & -1.344 & & & & \\
\hline Turboprop & & & -2.517 & 0.56 & 1.522 \\
\hline Foreign OD & 0.929 & 1.354 & -0.334 & & -0.236 \\
\hline Hub/Non-Hub Airport & 1.334 & & & & -0.692 \\
\hline Log Criticality Factor & 9.237 & 1.629 & 4.318 & & 1.707 \\
\hline Night Conditions & & & -1.36 & & \\
\hline
\end{tabular}

${ }^{\mathrm{a}}$ User Class F (Cargo), T/C (Taxi/Commuter), G (General Aviation).

\subsection{Wreckage location model}

The second component is the wreckage location model. Capability of estimating the final location of the aircraft due to the accident is of great interest to analysts. Predicting the likelihood that the aircraft will pass the RSA boundaries or strike any obstacle would be necessary in performing runway risk assessment.

The function of the location model is to calculate the probability of an aircraft to stop beyond a certain threshold from the runway side or end. Obviously, this probability is not equal for all location points around the runway but generally decreases with larger distances from the runway.

Similar to the event probability model, the wreckage location model is also specific for the event type. Therefore, five models can be developed. These wreckage location models are based on historical accident data for all five types of associate events. In formulating these models, many factors would affect separately each type of accident. For instance, in the case of overruns, the wreckage location would be altered by the type of terrain, for instance; paved, unpaved, and existence of Engineered Materials Arrestors System - EMAS.

The assumptions regarding the axis locations to describe wreckage events are depicted in Figs. 11-13 (Ayres et al., 2013).

The distribution of wreckage locations relative to the runway was modeled by ACRP through statistical functions. For the longitudinal distribution, the basic model is:

$P($ Location $>x)=e^{-a x^{n}}$

where $\mathrm{P}\{$ Location $>\mathrm{x}\}$ is the probability the overrun/undershoot distance along the runway centerline beyond the runway end is greater than " $x$ ", " $x$ " is a certain location or distance beyond the runway end, and "a" and "n" are regression coefficients. A typical longitudinal wreckage probability location distribution is depicted

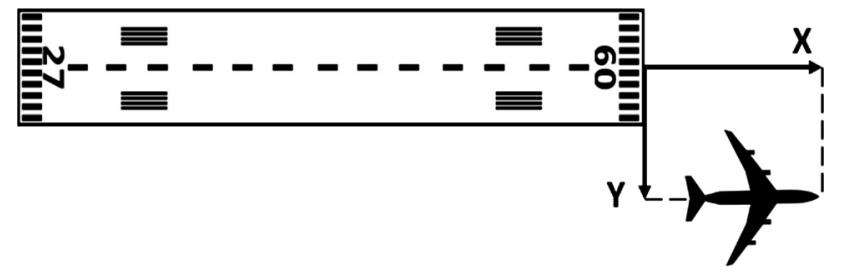

Fig. 11. $X-Y$ origin relevant for aircraft overruns.

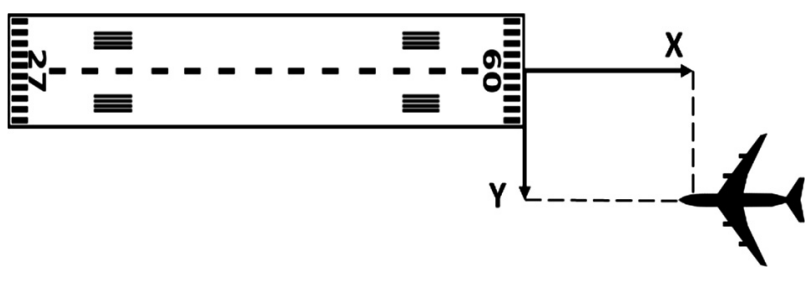

Fig. 12. $X-Y$ origin relevant for aircraft undershoots.

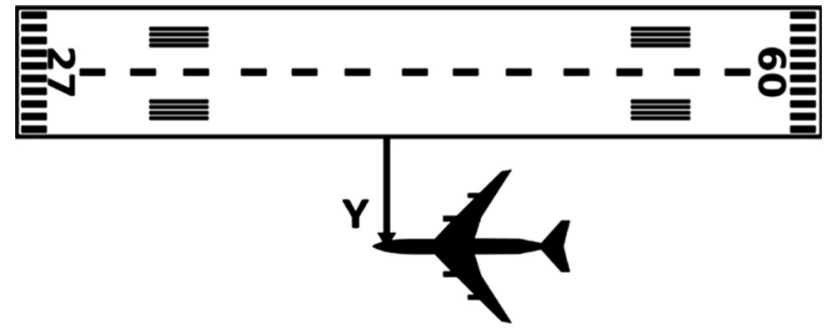

Fig. 13. Y origin relevant for aircraft veer-offs. 


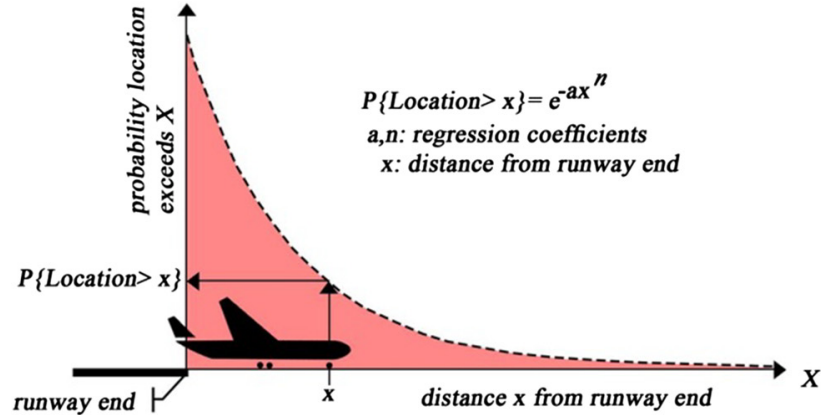

(a)

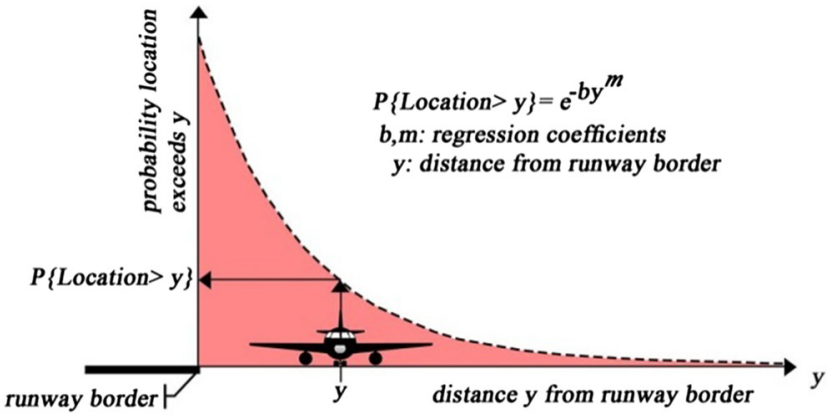

(b)

Fig. 14. Reference scheme for the FAA ACRP for (a) Probability distribution for aircraft overruns and (b) Probability distribution for aircraft veer-offs.

Table 5

Reference table for the FAA - ACRP for regression coefficients values used for wreckage location model.

\begin{tabular}{llll}
\hline $\begin{array}{l}\text { Type of } \\
\text { accident }\end{array}$ & $\begin{array}{l}\text { Wreckage location } \\
\text { regards to axes }\end{array}$ & $\begin{array}{l}\text { Model regression } \\
\text { coefficients values }\end{array}$ & $\mathrm{R}^{2}(\%)$ \\
\hline LDOR & $\mathrm{X}(\mathrm{a}, \mathrm{n})$ & $P[$ location $>x]=e^{-0.00321 x^{0.984941}}$ & 99.8 \\
LDOR & $\mathrm{Y}(\mathrm{b}, \mathrm{m})$ & $P[$ location $>y]=e^{-0.20983 y^{0.4862}}$ & 93.9 \\
LDUS & $\mathrm{X}(\mathrm{a}, \mathrm{n})$ & $P[$ location $>x]=e^{-0.01481 x^{0.751499}}$ & 98.7 \\
LDUS & $\mathrm{Y}(\mathrm{b}, \mathrm{m})$ & $P[$ location $>y]=e^{-0.02159 y^{0.773896}}$ & 98.6 \\
LDVO & $\mathrm{Y}(\mathrm{b}, \mathrm{m})$ & $P[$ location $>y]=e^{-0.02568 y^{0.803946}}$ & 99.5 \\
TOOR & $\mathrm{X}(\mathrm{a}, \mathrm{n})$ & $P[$ location $>x]=e^{-0.00109 x^{1.06764}}$ & 99.2 \\
TOOR & $\mathrm{Y}(\mathrm{b}, \mathrm{m})$ & $P[$ location $>y]=e^{-0.04282 y^{0.659566}}$ & 98.7 \\
TOVO & $\mathrm{Y}(\mathrm{b}, \mathrm{m})$ & $P[$ location $>y]=e^{-0.01639 y^{0.063461}}$ & 94.2 \\
\hline
\end{tabular}

in Fig. 14(a). Regression coefficients "a" and " $n$ " are provided in Table 5.

Similar model structure has been developed for the transversal distribution. The model can be represented by the following equation:

$P($ Location $>y)=e^{-b y^{m}}$

where $\mathrm{P}\{$ Location $>\mathrm{y}\}$ is the probability the accident occurrence distance from the runway border (veer-offs) or centerline (overruns and undershoots) is greater than "y", "y" is a given location or distance from the extended runway centerline or runway border, and "b" and "m" are regression coefficients. A typical wreckage lateral location probability distribution is depicted in Fig. 14(b). Regression coefficients "b" and "m" are provided in Table 5.

\subsection{Consequence model}

When an incident/accident occurs on airports this may lead to multiple fatalities, aircraft destruction, or structural damages to buildings; each consequence can be associated to a severity level according to the FAA classification (FAA, 1989). Although cleared and graded runway safety areas can provide some protection in most of the accidents and can decrease the consequences, there are rare conditions in which aircrafts could be out of control and lead to possible fatalities and damages.

The consequence model should provide a qualitative severity assessment of an accident, by correlating the relevant location model and information related to the airport characteristics such as dimensions of existing RSA, airplane weight, location and type of obstacles, and topography of surrounding terrain.

In particular, two factors can change the magnitude of the consequences; type of obstacle structures and the level of energy released during the collision. Aircraft speed when colliding with obstacles is the main factor that determines the energy of aircraft. In other words, higher speeds would lead to more severe consequences. In addition, the more rigid is the obstacle, more severe the consequences that should be expected. The following variables are listed as influencing factors on consequences' severity by ACRP (Ayres et al., 2013); obstacle type and size, aircraft size and speed, and number/location of obstacles.

\section{Risk assessment of runway and RSA}

Safety areas, which are consisted of longitudinal strip and RESA (Runway End Safety Area), are designed to mitigate the possible consequences of incident and accidents nearby the runway.

In particular, the role of RESA is noticeable when aircrafts undershoot or overrun the runway and is to minimize the risk of accident related both to aircrafts and passengers and in case of occurrence, to mitigate the consequences. The longitudinal strip is the surrounding area located along the runway in order to decrease the damages as a result of potential aircraft veer-offs.

ICAO has recently strengthened its Standards and Recommendations for the provision of RESA. The previous Recommendation for RESA longitudinal dimension was $90 \mathrm{~m}$ and has been now converted to $240 \mathrm{~m}$. The total recommended longitudinal protection after the runway threshold, including the $60 \mathrm{~m}$ strip, has therefore been doubled from 150 to $300 \mathrm{~m}$ for the longest runways (ICAO, 2013).

The relation between runway lengths required/available at airport is one of the most important factors in computing accident probability. Runway length required is divided into two major subcategories, which are LDR (Landing Distance Required) and ASDR (Acceleration/Stop Distance Required). LDR is related to the landing phase of flight and identifies the minimum landing distance required plus a safety factor. In contrary, ASDR is related to the take-off phase in case of aborted take-off.

The following sections evaluate how specific impacting parameters affect the probability of occurrence of runway-related accidents by simulating three diverse case-studies airports in related landing and take-off phases of flights. All considered boundary conditions are explained in the context.

\subsection{Case-studies}

In order to simulate the probability of occurrence of runwayrelated accidents based on normal operational data three airports have been specifically selected as case studies. Selection has been based on different factors such as location, climate pattern, volume of traffic, characteristics of the runway and RSA, surrounding ground/water constrains, and availability of data. Information about the airports is depicted in Table 6. 
Table 6

A brief summary on case-studies detail information.

\begin{tabular}{|c|c|c|c|}
\hline Case-study & A1 & $\mathrm{A} 2$ & A3 \\
\hline Airport type & Public & Public & Public \\
\hline Elevation AMSL (m) & 238 & 12 & 17 \\
\hline \multirow[t]{2}{*}{$\operatorname{ASDA}^{a}(\mathrm{~m})$} & 2875 RWY 10 & 2436 RWY 08 & 1738 RWY $02 \mathrm{~L}$ \\
\hline & 2875 RWY 28 & 2436 RWY 26 & 1738 RWY 20 R \\
\hline \multirow[t]{2}{*}{$\operatorname{LDA}^{\mathrm{b}}(\mathrm{m})$} & 2655 RWY 10 & 2340 RWY 08 & 1738 RWY $02 \mathrm{~L}$ \\
\hline & 2741 RWY 28 & 2350 RWY 26 & 1738 RWY 20 R \\
\hline RWY pavement & Asphalt & Asphalt & Asphalt \\
\hline Annual Traffic Growth (\%) & 2.5 & 10.2 & 2 \\
\hline Category of ILS & CAT III on RWY 28 & CAT I on RWY 08 & CAT I on RWY $20 \mathrm{R}$ \\
\hline Reason for selecting it & $\begin{array}{l}\text { Location, severe winds, } \\
\text { high humidity and heavy rains }\end{array}$ & High annual traffic growth & $\begin{array}{l}\text { Runway geometry and } \\
\text { RSA dimension (shorter) }\end{array}$ \\
\hline
\end{tabular}

a Accelerate-Stop distance available for take-off (ASDA).

b Landing Distance Available (LDA).

The first airport is one of the busiest airports in Italy, mainly subject to low-cost traffic (category $C$ aircrafts according to ICAO; i.e. Boeing 737 and Airbus 318-319). Accelerate-Stop Distance Available for take-off (ASDA) is $2875 \mathrm{~m}$ for both directions of the single runway and Landing Distance Available (LDA) is $2655 \mathrm{~m}$ for RWY head 10 and $2741 \mathrm{~m}$ for RWY head 28. Runway length is $2875 \mathrm{~m}$. This airport is land locked by a river from one side and residential areas on the other side. The location and weather condition of this airport is the reason of its selection as a case study; it is indeed exposed to severe winds, high humidity and heavy rain. The layout of the runway and RESA with the related dimensions is depicted in Fig. 15.

The second airport is subject to mixed traffic (both low-cost and national carriers) and was chosen due to the high level of traffic as well as the massive annual traffic growth (+10.2\% in 2014). ASDA is
$2436 \mathrm{~m}$ for both directions of the single runway and LDA is $2340 \mathrm{~m}$ for RWY head 08 and $2350 \mathrm{~m}$ for RWY head 26. Runway length is $2436 \mathrm{~m}$. This airport is land locked by the sea from one side. The layout of this runway and RESA with the related dimensions and Displaced Threshold of Runway (DTHR) is depicted in Fig. 16.

The third airport is defined as to be a primary small commercial service airport since it had almost 10,000 passengers per year between 2011 and 2015. The main runway, $1738 \mathrm{~m}$, is one of the shortest in the United States, and passenger airliners at the airport have never used larger aircrafts than the medium ICAO aircraft category. Since there is not any displaced threshold for this runway, ASDA and LDA for both runway directions are $1738 \mathrm{~m}$. This airport is city-based and surrounded by residential areas. It was mainly chosen for the small runway length and RSA dimensions. The layout is depicted in Fig. 17.

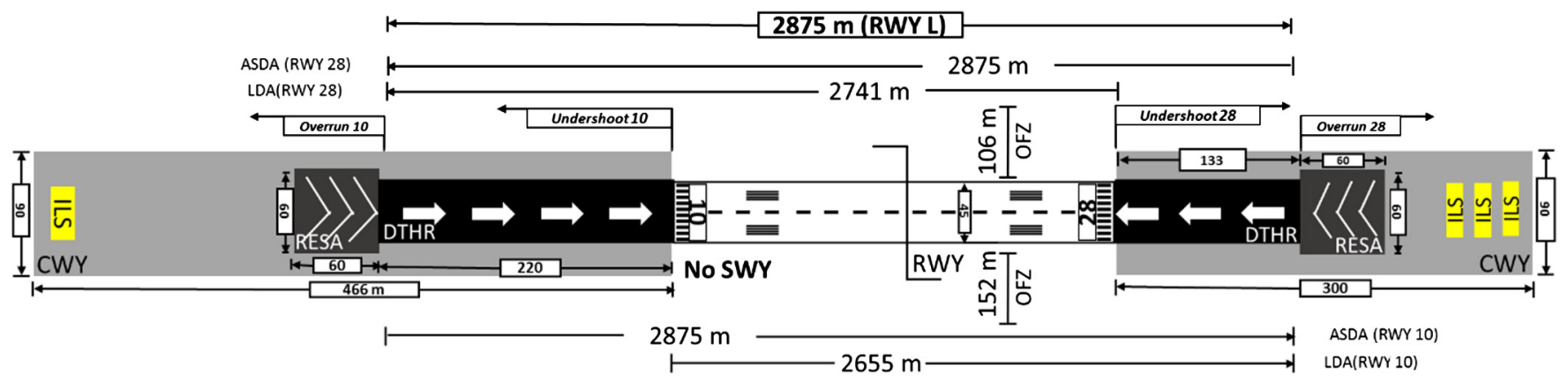

Fig. 15. Case-study 1 runway and RSA layouts.

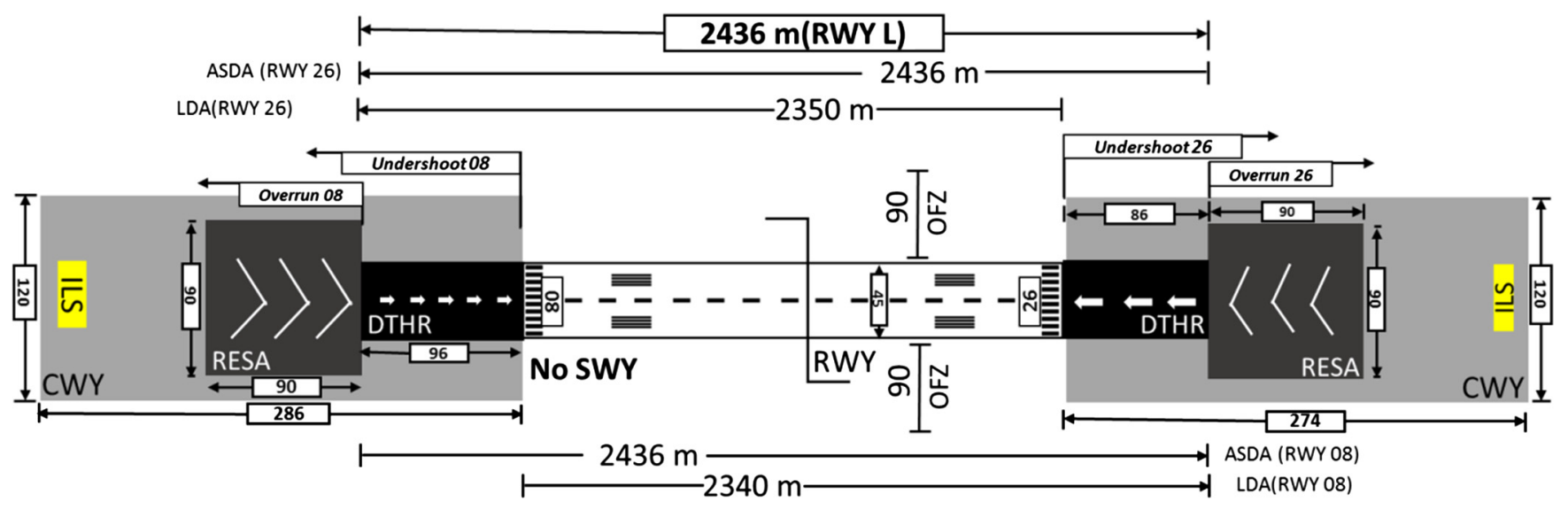

Fig. 16. Case-study 2 runway and RSA layouts. 


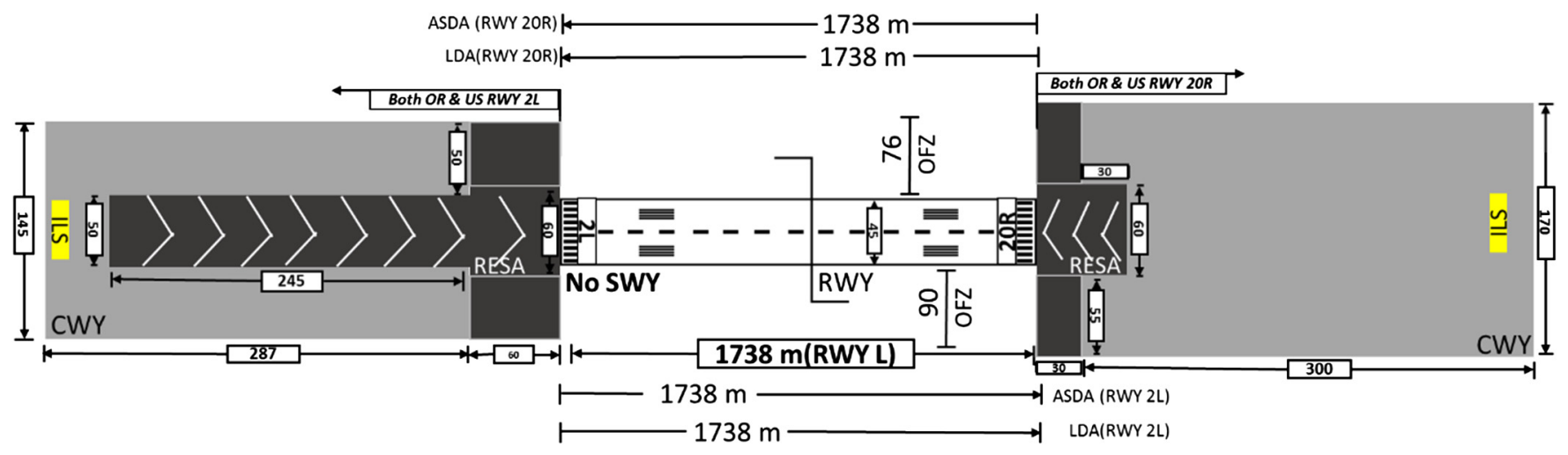

Fig. 17. Case-study 3 runway and RSA layouts.

\subsection{Operational and weather data of selected airports}

To assess the associate risk of the three runways, providing two main types of data is necessary: Historical Operations Data (HOD) and Historical Weather Data (HWD). The historical operational data is based on annual normal operational data (NOD) of a specific airport. Taking advantages of using NOD is one of the approaches of recent studies for modeling risk (ACRP report 3, 2008).

Historical operations data has been collected for each case study and for one year time span. In the case of towered airports, operational data records can be extracted from tower logs for the entire period of observation. Sometimes, HOD records are extractable but the runway usage is not determined. In contrary, for nontowered airports, since there is not any fix recording system a sample of operations for three months was recorded as to form a preliminary database to be then extended over the one-year period of records. Each historical weather data should be coupled with one HOD and the probability of associated accidents should be simulated for each historical operation. The probability distribution for each type of incident is then given as output.

For case-study A1, 72,318 HOD and 13,283 HWD records were identified. HOD records contained date and time, aircraft model (FAA code), runway ID, type of operation, flight category, and flight type. Records of HWD covered one year historical operations and include date/time, wind direction, wind speed, temperature, precipitation, visibility, ceiling, and weather conditions. For casestudy A2, 45,956 HOD and 17,520 HWD records were collected, and for case-study A3, 97,106 HOD and 8760 HWD records were provided.

\subsection{RSARA simulation (base scenario)}

In order to initiate the analysis input data is required. First, airport historical operational data of the three airports between Jan 1 , 2014 and Jan 1, 2015 was gathered. Secondly, airport historical weather data covering similar period was collected. Moreover, information in regards to characteristics of runway (elevation, declared distances, displaced threshold, direction, and length), characteristics of RSA (geometry, pavement material, presence of EMAS) and obstacles (size, location, and obstacle category) was also collected. Finally, general information about annual growth rate and airport annual traffic volume was acquired.

Although different methodologies are available in assessing runway accident probability, proper and comprehensive software is still lacking.

A report is generated at the end of the analysis with summaries on average probability for each type of incident for the associated runway, RSA section, and the overall airport. The expected number of years before an accident will probably occur is given as output depending on annual traffic volume and traffic growth rate. Also, it is indicated the percentage of operations subject to an accident probability higher than a user-defined target level of safety (TLS). The target level of safety selected for this specific study is $1.0 \mathrm{E}-6$ (one event per one million movements). The reasoning behind this selection is that the percentage of operations subject to a probability lower than this target level of safety can be considered negligible and designing a runway with higher safety factor would not be reasonable due to economic considerations. Further information about the software can be found in ACRP report 50 (ACRP report 50, 2011).

A summary of average probability of associated incidents for individual runways of the three selected airports (A1, A2, A3) running in normal operation scenario at year 2014 is shown in Table 7.

As it can be interpreted from the results the average probability of veer-off incident for both landing and take-off phase is lower than the average probability of undershooting or overrunning the runway as it was expected. In addition, take-off veer-off incident is less probable than landing veer-off since inclination is less likely to occur during take-off phase because of the greater control of the pilot on the airplane direction due to the initial reduced speed.

\subsection{Sensitivity analysis via RSARA}

In this section RSARA software was used to conduct sensitivity analyses on results of Section 5.3. Sensitivity analyses were then conducted to identify the weight different input parameters have

Table 7

Average probability of occurrence.

\begin{tabular}{|c|c|c|c|c|c|c|}
\hline \multirow{2}{*}{$\begin{array}{l}\text { Case-study } \\
\text { Runway }\end{array}$} & \multicolumn{2}{|c|}{ Airport (A1) } & \multicolumn{2}{|c|}{ Airport (A2) } & \multicolumn{2}{|c|}{ Airport (A3) } \\
\hline & RWY 10 & RWY 28 & RWY 08 & RWY 26 & RWY 2L & RWY 20R \\
\hline LDOR & $3.11 \mathrm{E}-07$ & $2.69 \mathrm{E}-07$ & $2.89 \mathrm{E}-07$ & $2.42 \mathrm{E}-07$ & $1.88 \mathrm{E}-07$ & $2.65 \mathrm{E}-07$ \\
\hline TOOR & $3.40 \mathrm{E}-07$ & $3.11 \mathrm{E}-07$ & $4.17 \mathrm{E}-07$ & $4.16 \mathrm{E}-07$ & $1.30 \mathrm{E}-07$ & $1.35 \mathrm{E}-07$ \\
\hline LDUS & $3.10 \mathrm{E}-07$ & $4.86 \mathrm{E}-07$ & $2.47 \mathrm{E}-07$ & $2.58 \mathrm{E}-07$ & $1.91 \mathrm{E}-07$ & $1.56 \mathrm{E}-07$ \\
\hline LDVO & $8.73 \mathrm{E}-08$ & $8.07 \mathrm{E}-08$ & $7.90 \mathrm{E}-08$ & $8.71 \mathrm{E}-08$ & $2.13 \mathrm{E}-07$ & $1.74 \mathrm{E}-07$ \\
\hline TOVO & $8.90 \mathrm{E}-09$ & $8.57 \mathrm{E}-09$ & $4.78 \mathrm{E}-09$ & $5.22 \mathrm{E}-09$ & $2.29 \mathrm{E}-08$ & $2.19 \mathrm{E}-08$ \\
\hline
\end{tabular}


on increasing or decreasing the probability of possible incidents during aircraft operations. Parameters were singularly altered and the software was rerun to determine their level of significance. For each case-study a limited set of parameters has been chosen as follows.

- Airport A1 - Variation in the average probability of occurrence as a result of changes in weather input data; in this part of the study, Historical Weather Data was solely modified and all other input parameters were kept the same. In this regard two mock scenarios of weather data condition were made up. In addition, one scenario, namely the normal weather scenario, includes the exact recorded climate data on one year for the specific airport.

The first mock scenario represented the best possible weather case that would decrease the probability of occurrence to its minimum. Ceiling, visibility, temperature and wind speed were modified accordingly; instead, unfavorable weather conditions such as precipitation, snow, ice, and mist were not included in this scenario.

The second mock scenario, namely the worst possible weather condition, was developed as to include all unfavorable weather extreme conditions (i.e.; crosswinds, rain, ice, and snow). This scenario was created by choosing the weather-related parameters which are known for their degree of danger during airport operations and thus leading to higher risk probability.

Variation in the average risk of accident as a result of changes in RESA geometric layout and material; four different scenarios were chosen. The Normal scenario which is the real RESA geometry of the runway for the specific airport, a 'fully-paved' scenario which assumed the RESA to be fully paved with asphalt, a 'total-grass' scenario which considered the RESA to be fully covered by grass, and 'total-EMAS' scenario in which an arrestor-bed was installed in the RESA.

Variation in the average probability of occurrence as a result of changes in ILS approach categories; ILS approach types are divided into three categories according to ICAO Annex 14; CAT I, CAT II, and CAT III depending on the visibility requirements to operate in the airport. Five different scenarios were introduced; runways with their current category of approach, runway without ILS, runway with CAT I, runway with CAT II, and runway with CAT III approach category.

\section{- Airport A2;}

Variation in the average probability of occurrence as a result of changes in weather input data; the same procedure as developed for airport A1 was followed.

Variation in the average number of years before an event occurs as a result of changes in the expected annual traffic growth rate; although expected annual traffic growth rate is one of the critical issues that is always under evaluation by aviation authorities, the impact of this factor is not negligible. It is common that annual traffic growth rate for airport would be predicted. For instance, for A2 case-study the value for 2014 was found to be $10.2 \%$, which seemed to be common value among fast-growing European airports in 2014. In this regard, five different annual traffic growth rates were selected for the analysis; specifically, $10.2 \%, 8 \%, 6 \%, 4 \%$ and $2.5 \%$.

\section{- Airport A3;}

Variation in the average probability of occurrence as a result of changes in weather input data parameters; the same procedure as developed for airport A1 and A2 was followed.
Variation in the average probability of occurrence as a result of changes in runway length; A3 was selected due to its very short runway (almost $1700 \mathrm{~m}$ ) respect to the moving traffic operating on the airport. Four scenarios were considered. The first and the second scenarios reduced the runway length by $300 \mathrm{~m}$ and $600 \mathrm{~m}$, respectively; the third and the fourth scenarios added $300 \mathrm{~m}$ and $600 \mathrm{~m}$ to A3 runway length.

\subsection{Analysis of results and discussion}

Some airports, due to their topology and layout, do not have the ability to allocate enough space for safety areas and RESA. There are many factors and reasons that lead to these deviated situations from the standards and regulations, which are called nonconformities. Each type of nonconformities would convert into a risk. This risk can get higher or lower depending on the level of standard violations (de Castro Fortes and Correia, 2012). In this regard, investigating the level of importance of different parameters and factors which have influences on the output risk values is the main focus of this section.

\subsubsection{Results and discussion for airport $A 1$}

- Variation in the average probability of occurrence as a result of changes in weather input data parameters

Normal weather case scenario is dedicated to real data from one year recording of movements in Airport 1. Beside normal scenario two other scenarios, which are worst and best weather cases, were defined for understanding the influence of different weather parameters on the probability of runway-related accidents occurrence. As it can be seen in Fig. 18, the worst case weather scenario shows highest probability of occurrence in all five types of accidents. Specifically, the worst weather case increases significantly the probability of LDOR, TOOR, LDUS, LDVO and TOVO by 2, 3, 2, 4 , and 2 order of magnitude respectively. In the worst case weather scenario the maximum probability of occurrence is shown during LDVO due to notably decrease in pavement friction in existence of ice/snow/rain, plus effective increase of crosswind. TOOR shows also notable increase in probability of occurrence due to extreme tailwind effects and decreased pavement friction. Lower visibility and control ability due to increase in wind, mist, gust, rain, ice, and snow, in particular, led to an increase in occurrence probability during landing of up to four orders of magnitude. Reduced control of the airplane is in fact expected by the pilot on the runway during bad weather conditions. The best case weather scenario, as expected, reduced the probability of occurrence although reductions ranged within one order of magnitude respect to real weather situation of A1 - normal scenario. In the other word, this scenario decrease the probability of LDOR, TOOR, LDUS, LDVO and TOVO by $-88 \%,-20 \%,-86 \%,-90 \%$, and $-81 \%$, respectively, compared to the normal scenario.

TOVO values for different scenarios are quite close to each other, several reasons can lead to this fact; generally runways are oriented as to follow the main wind direction. Plus in case of heavy rain and snow, for instance, the aircraft movement is started at zero-speed. This also proves that the landing phase of a flight is likely to be affected more significantly than take-off by inclement weather; in addition, weather affects more overrun accidents than undershoots (by one order of magnitude).

\section{- Variation in the average risk of accident as a result of changes in RESA geometric layout and pavement material}

Different RESA pavement materials would affect the probability of accidents and their consequences; therefore, the results would be altered just if probability of risk (probability of hazard 


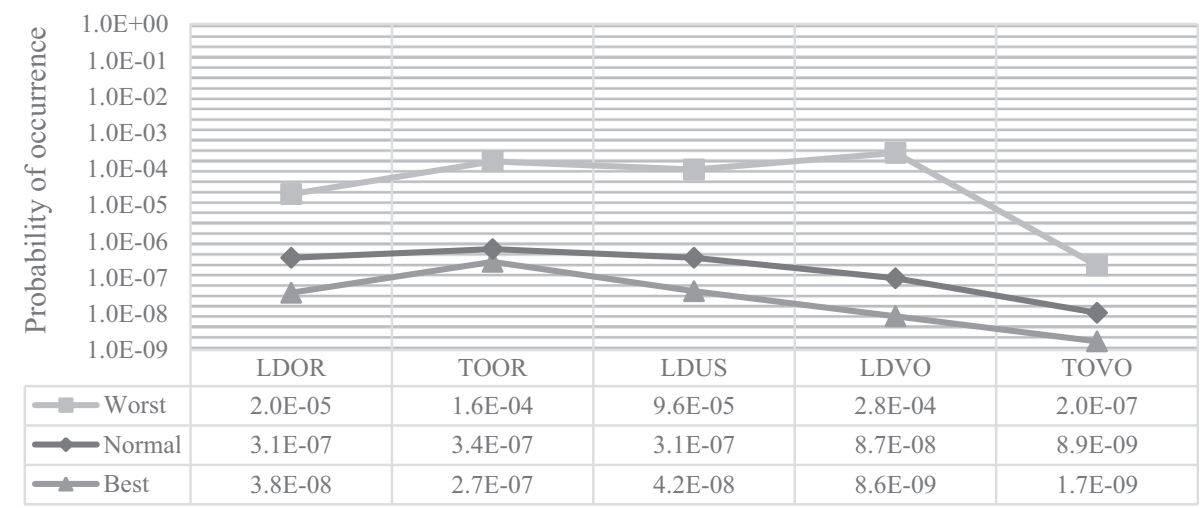

Fig. 18. Relationship between variation in Weather Data and average probability of occurrence.

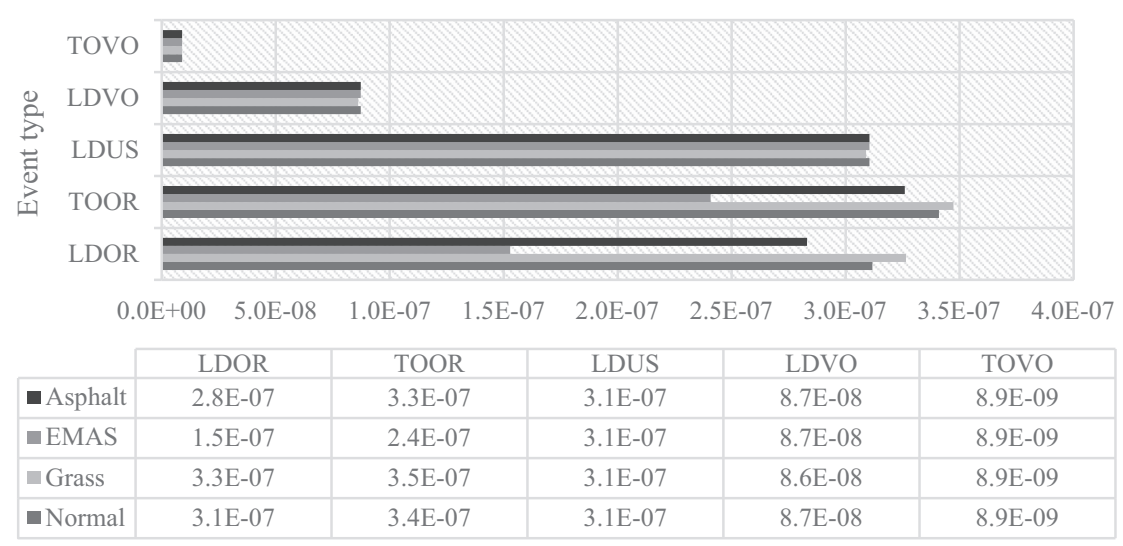

Fig. 19. Relationship between variation in RESA paving material and average probability of occurrence.

occurrence and consequences) is calculated. As it can be interpreted from Fig. 19, there would not be any change in probability for take-off and landing veer-off and landing undershoot, since changes affected only the runway end safety area. For instance, equipping the runway end safety area with EMAS decrease the probability of occurrence of LDOR, TOOR, LDUS, LDVO, and TOVO by $51 \%, 29.4 \%, 0 \%, 0 \%$, and $0 \%$ respectively. The reasoning behind $0 \%$ variation in undershoot and veer-off accidents is that EMAS affects only the probability of overrun accidents since it is only installed within the RESA.

EMAS, which consists of crushable material, is located within the runway end safety area. No external energy source is required for this overrun mitigation measure since it is designed as a passive system. EMAS material should be highly crushable, such as lowdensity concrete, but still durable that due to aircraft's self-weight, wheels crush the arrestor material. In this regard the developed drag force on wheels led to aircraft deceleration until it fully stops. (Heymsfield, 2013).

Generally, it is observed that the presence of EMAS results in lower probability of occurrence of LDOR up to $-50 \%$ compared to asphalt-paved RESA, whereas grass covered RESA generally has the highest probability of occurrence compared to the other systems.

\subsubsection{Results and discussion for airport A2}

- Variation in the average probability of occurrence as a result of changes in weather input data;

For the second case-study similar weather scenarios were defined as in Airport 1. The results of this simulation showed that the worst weather scenario increased significantly the probability of LDOR, TOOR, LDUS, LDVO and TOVO by 2, 3, 3, 5 , and 2 order of magnitude, respectively. Best weather scenario instead decreased the probability of LDOR, TOOR, LDUS, LDVO and TOVO by $-63 \%,-3 \%,-64 \%,-36 \%$, and $-18 \%$, respectively, compared to the normal scenario. The main differences with Airport 1 are to be investigated in relationship to the air traffic spectrum which also includes a greater amount of smaller aircraft compared to Airport 2; those aircraft are commonly more prone to strong wind. However, the magnitude of changes due to weather is consistent among $A 1$ and A2. Interpretation of results of this simulation and the reasoning behind them are similar to A1.

- Variation in the average number of years between an event occurs as a result of changes in the expected annual traffic growth rate

Fig. 21 shows the variation in annual traffic growth rate and respective changes in numbers of years between events. Increasing the annual traffic results in decreasing the number of years between the expected events. For instance, the estimated years between two LDOR accidents, in case of $2.5 \%, 4 \%, 6 \%$, and $8 \%$ annual traffic growth rate, are increased by $2.5,1.9,1.4$, and 1.2 times respectively.

Generally, the numbers of years between events due to overruns both in landing and takeoff phases of flight are smaller (greater probability of occurrence). Solid lines in Fig. 21 are not extended beyond 100 years because that value was assumed as a reasonable threshold for airport planning purposes. 


\subsubsection{Results and discussion for airport $A 3$}

- Variation in the average probability of occurrence as a result of changes in weather input data;

For the third case-study similar weather scenarios were defined as for Airport 1 and 2. The results of this simulation show that the worst weather scenario increased significantly the probability of LDOR, TOOR, LDUS, LDVO and TOVO by 2, 3, 3, 5, and 1 order of magnitude, respectively. Best weather scenario instead decreased the probability of LDOR, TOOR, LDUS, LDVO and TOVO by $-63 \%$, $-16 \%,-65 \%,-44 \%$, and $-75 \%$, respectively, compared to normal scenario. As a result of this sensitivity analysis it can be interpreted from Figs. 18, 20, and 22 that for airport A3 which has the shortest length, probability of overrun is bigger than A1 and A2 because of the smaller length.

It should be noted that large aircrafts commonly land with higher touchdown speed and greater Maximum Landing Weight (MLW) compared to lighter aircraft categories. These two factors increase the required braking distance under the circumstances of runway contaminations such as rain, ice and snow. Moreover, tailwind, headwind and crosswind also affect the probability of landing overrun occurrence due to bigger hull and wing area of heavier aircrafts. Despite of aforementioned effects due to aircraft categories, in this study it was assumed that traffic mix do not

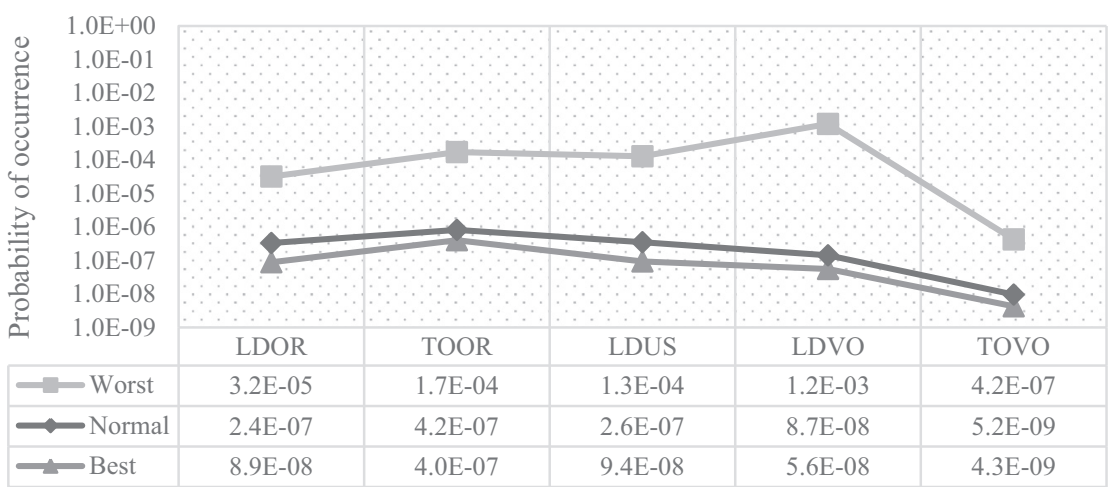

Fig. 20. Relationship between variation in WD and the output of average probability of incident outside RSA.

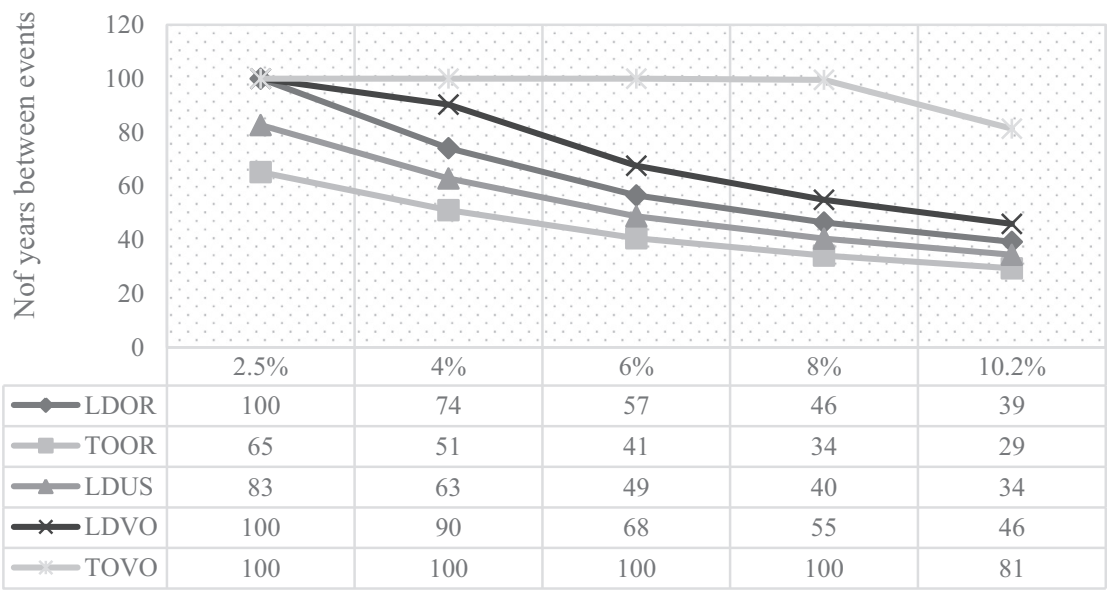

Fig. 21. Relation between the expected annual traffic growth rates with the number of years between events.

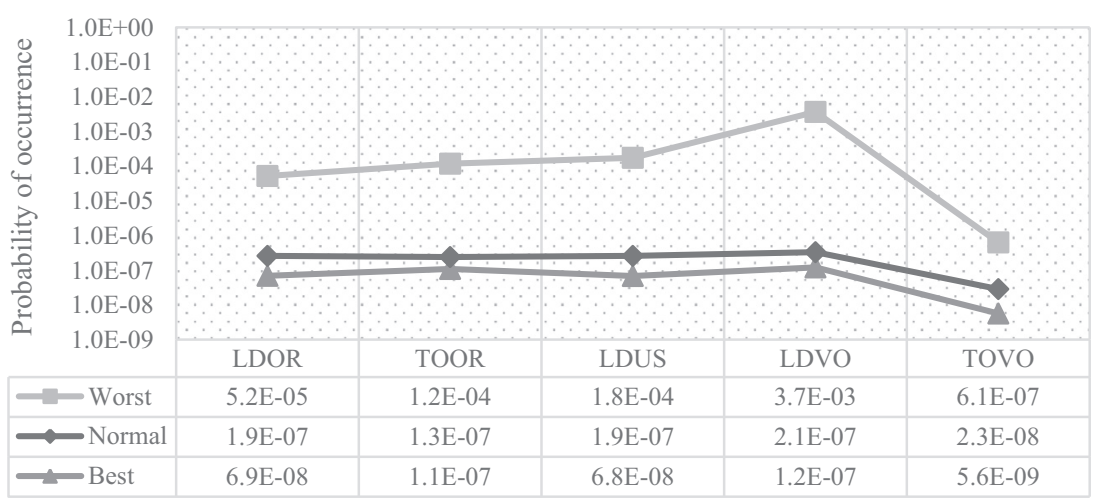

Fig. 22. Relationship between variation in WD and the output of average probability of occurrence. 


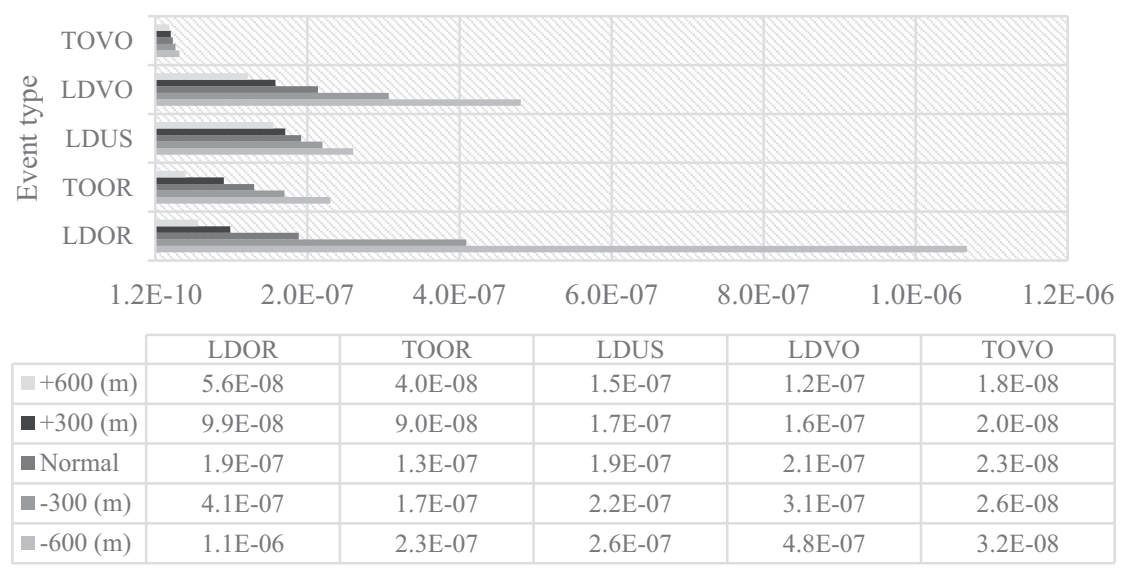

Fig. 23. Relation between variation in runway length and the output average probability of occurrence.

affect probability of occurrence due to different weather conditions.

- Variation in the average probability of occurrence as a result of changes in runway length

Fig. 23 shows that the changes in runway length affect the probability of event occurrence. Shorter runway length leads to greater probability of occurrence. In particular, additional $+600(\mathrm{~m})$ to runway length led to decrease in probability of occurrence of LDOR, TOOR, LDUS, LDVO, and TOVO by $-70 \%,-69 \%,-19 \%$, $-43 \%$, and $-20 \%$, respectively. Reducing the runway length of $-600(\mathrm{~m})$ led to increase the probability of occurrence of LDOR, TOOR, LDUS, LDVO, and TOVO by $+466 \%,+77 \%,+36 \%,+125 \%$, and $+38 \%$, respectively. Variation in runway length affects overrun accidents, mainly during landing, more than undershoots. For instance $+116 \%$ probability in LDOR for 300 m runway reduction while only $+14 \%$ increase for LDUS. Events related to landing LDOR, LDUS and LDVO have higher probability of occurrence when the runway gets shorter; in particular, runway length proved to be one of the main parameter to affect probability and thus risk.

\section{Conclusions}

The statistical sensitivity analysis on recorded incidents/accidents shown that the number of accidents is greater than incidents in all phases of flight; this is also related to the tendency of airport authorities not to record the majority of minor incidents.

Meteorological conditions affect the number of events occurred during VMC, which are greater than the IMC. Airports equipped with instrumental landing system facilities greatly reduce the probability of landing accidents during IMC and adverse weather conditions (Fig. 9).

Among the four main FAA categories of airports, the P-CS and GA have the highest number of occurred events. P-CS airports are, in fact, well-facilitated and equipped with state-of-the-art facilities and operational instrumental aids. The high number of event occurrence in these types of airport is mostly due to the high traffic volumes. In addition, GA airports exhibit large number of events due to the small size of operating aircrafts and lack of advanced equipment, such as navigational aids.

Building on the findings from the statistical analysis, several sensitivity evaluations were conducted on three real airports with

Table 8

(a) Incident probability due to climate conditions, (b) average number of years between the occurrence of two incidents, (c) incident probability due to different RWY lengths.

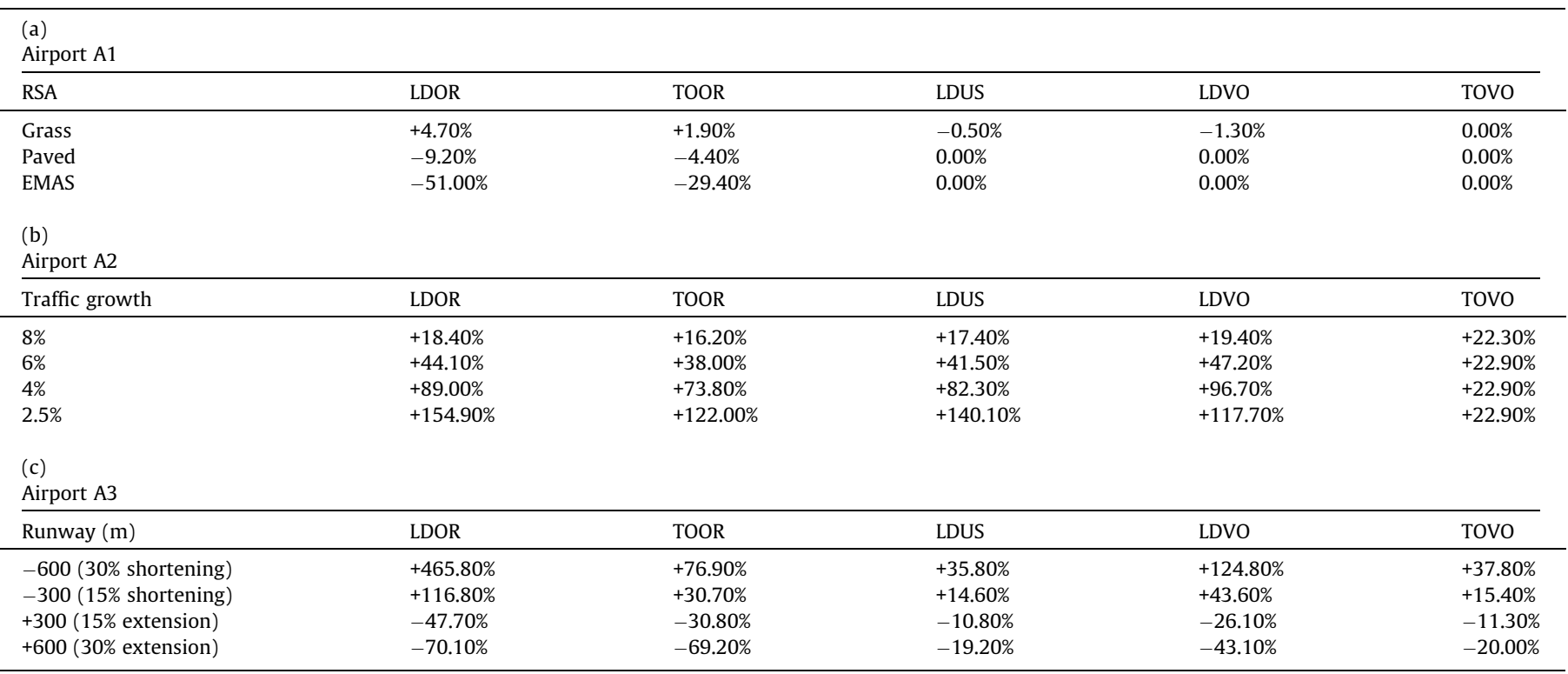


real operational data and climate conditions; based on the results the following conclusions can be drawn:

\section{- Airport A1}

Weather condition; three possible weather scenarios were considered; the optimal weather condition, the worst and the current real scenario. As it can be interpreted from the results, the average probability of risk in the case of optimal weather condition scenario leads to the lowest probability of occurrence. Factors such as wind gusts (especially crosswinds), rain, ice and snow greatly affected the probability of occurrence of a critical event, increasing the chance of an incident up to three orders of magnitude. Weather confirmed to be one of the most significant factors in airport risk assessment.

Runway Safety Area characteristics; three RSA scenarios were defined and investigated; fully-paved RSA, fully-grass covered RSA, and RSA with EMAS. The results of the analysis ranked the probability of event occurrence beyond the RSA limits as to be higher for RSA covered with grass, followed by the fully-paved scenario and the scenario with RSA plus EMAS, respectively. The provision of EMAS greatly reduced the chances of an overrunning aircraft to overpass the RSA limits thus reducing the probability of incidents. Table 8 a shows the percentage of variation according to the RSA characteristics.

\section{- Airport A2}

Annual traffic growth rate; airport A2 was chosen due to its high annual traffic growth rate. It had $10.2 \%$ annual traffic growth rate in 2014 and this figure was considered as the reference for the sensitivity analysis. Four additional scenarios were defined for the calculations; $8 \%, 6 \%, 4 \%$ and $2.5 \%$ of annual traffic growth rates. The outcomes were related to the number of years between two consecutive incidents. The number of years between the events (frequency of occurrence) increases with the decrease in annual traffic growth rate. The percentage of variation expressed as the average number of years between two consecutive events under different traffic growth rates were depicted in Table $8 \mathrm{~b}$.

\section{- Airport A3}

Length of the runway; airport A3 is one of the airports with the shortest runway length. Four scenarios were considered. The first two included shortening the length of the available runway length by $300 \mathrm{~m}(-15 \%)$ and $600 \mathrm{~m}(-30 \%)$, respectively; the third and the fourth scenarios extended the runway length by $300 \mathrm{~m}$ and $600 \mathrm{~m}$, respectively. The increase in runway length decreases the probability of event occurrence as reported in Table $8 \mathrm{c}$.

\section{References}

AIRPORT COOPERATIVE RESEARCH PROGRAM, 2008. ACRP report 3, Analysis of Aircraft Overruns and Undershoots for RSA, National Academies of Sciences, Engineering, and Medicine. Transportation Research Board. http://dx.doi.org/ $10.17226 / 14137$.

AIRPORT COOPERATIVE RESEARCH PROGRAM, 2011. ACRP report 50, Improved Models for Risk Assessment of RSA, National Academies of Sciences, Engineering, and Medicine. Transportation Research Board. http://dx.doi.org/ $10.17226 / 13635$.

Ayres, M., Shirazi, H., Carvalho, R., Hall, J., Speir, R., Arambula, E., et al., 2013. Modelling the location and consequences of aircraft accidents. Saf. Sci. 51 (1), 178-186.

Aviation Safety Boeing Commercial Airplanes, 2016. Statistical Summary of Commercial Jet Airplane Accidents Worldwide Operations|1959-2015. Retrieved from Boeing website <www.boeing.com/news/techissues/pdf/ statsum.pdf>.

De Castro Fortes, J.L., Correia, A.R., 2012. Safety assessment at airports: são 42. paulo/congonhas airport - a case study. J. Braz. Air Transport. Res. Soc. 8 (1), 29-

Eddowes, M., Hancox, J., MacInnes, A., 2001. Final report on the risk analysis in support of aerodrome design rules Report for the Norwegian Civil Aviation Authority. AEA Technologies plc, Warrington, UK.

Federal Aviation Administration (FAA), 2012. Airport Design, AC 150/5300-13.

Guerra, L., Murino, T., Romano, E., 2008. Airport system analysis: a probabilistic risk assessment model. Int. J. Syst. Appl., Eng. Dev. 2 (2), 52-65.

Heymsfield, E., 2013. Predicting aircraft stopping distances within an EMAS. J. Transport. Eng. 139 (12), 1184-1193.

International Civil Aviation Administration, ICAO Annex 6 - Part 1, 2010. Operation of Aircraft - International Commercial Air Transport - Aeroplanes.

International Civil Aviation Administration, ICAO, 2013. Convention on international civil aviation - annex 14: aerodromes - aerodrome design and operations. Vol. 1. 6th ed.

International Civil Aviation Administration, ICAO 2013. Doc 9859, AN/474, Safety Management Manual (SMM), third ed.

Kirkland, I., Caves, R.E., Hirst, M., Pitfield, D.E., 2003. The normalisation of aircraft overrun accident data. J. Air Transp. Manage. 9 (6), 333-341.

National Transportation Safety Board (NTSB), 2005. Risk factors associated with weather-related General Aviation Accidents. Safety study, NTSB Number: SS0501, Washington DC, USA.

National Transportation Safety Board (NTSB), 2014. Review of US Civil Aviation Accidents, Calendar Year 2011. Annual Review NTSB/ARA-14/01, Washington, DC.

Roelen AA, Blom AHA, 2013. Airport safety performance. Modelling and Managing Airport Performance, Chapter 7, pp 171-208, ISBN: 978-0-470-97418-6.

Trucco, P., De Ambroggi, M., Leva, M.C., 2015. Topological risk mapping of runway overruns: a probabilistic approach. Reliab. Eng. Syst. Saf. 142, 433-443.

Valdés, R.M.A., Comendador, F.G., Gordún, L.M., Nieto, F.J.S., 2011. The development of probabilistic models to estimate accident risk (due to runway overrun and landing undershoot) applicable to the design and construction of RSA. Saf. Sci. 49 (5), 633-650.

Wagner, D.C., Barker, K., 2014. Statistical methods for modeling the risk of runway excursions. Risk Res. 17 (7), 885-901.

Wong, D.K., Pitfield, D.E., Caves, R.E., Appleyard, A.J., 2009. The development of a more risk-sensitive and flexible airport safety area strategy: Part I. The development of an improved accident frequency model. Saf. Sci. 47 (7), 903-912. 